\title{
Psychological Profiles Of Accountants And Accounting Majors: An Asian Study
}

Raymond M. Landry Jr., (E-mail: fblandry@ coba.panam.edu), University of Texas, Pan American

\begin{abstract}
Globalisation makes it inevitable for accounting professionals with diverse personalities to work under one roof. Such differences in behavioral patterns (Type A or Type B) impact performance in good and bad ways. This paper examines the psychological profile of Asian accounting professionals and accounting students using Type A or Type B behavior classifications. Examination of accounting professionals shows that Type $B$ is the most common behavior among all professionals sampled and contrary to previous research, Type B also tended to be common even in higher management levels of the accounting firms. Accounting students also showed similar patterns. Type $B$ behavior tended to be the most common psychological profile among both male and female accounting students while there is some evidence that Type A students do perform better as evidenced by self-reported grades. From the results, it is expected that future Asian accounting professionals to be dominated by Type B's. This behavior pattern may cause problems unless dealt with properly as Asian professionals interact with non-Asian business partners and clients who may tend more towards Type A behavior. While recognition of this won't remedy the problem, understanding the cause of this potential conflict is a first step in identifying a solution to this future dilemma.
\end{abstract}

\section{Introduction}

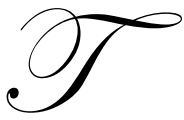

he Big Five have long ago realized that a global presence is important in order to remain competitive. This global presence necessitates the bringing together of people from a wide variety of backgrounds and cultures to service clients from many different countries including the Asian markets. As these staff auditors and consultants work together, it is very possible that staff of different nationalities with different social and cultural backgrounds will be working together. This interaction has both advantages and disadvantages. While a wide variety of backgrounds may be advantageous in bringing about diverse solutions, a disadvantage of this interaction may be the conflicts in work patterns. This may arise from persons working together with different mind-sets and behavioral patterns. Possible frictions between peer-to-peer or superiors and subordinates may affect staff morale and productivity. Some examples of these possible conflicts include:

- $\quad$ A relax-natured employee in a CPA firm is always in dispute with his manager because the manager is very hard-driven and impatient, and is always pushing him to finish his work quickly even though there is no urgent deadline.

- A very productive employee is ostracized in office because he is too competitive, aggressive and hostile, and upsets everyone who does not have similar traits.

As the large accounting firms expand their global presence, it is important to understand the potential conflicts that may arise due to opposing personality profiles. In this study, the psychological profile of accounting professionals and accounting majors in Singapore is examined. Results of this study are compared against previous studies and analyzed regarding future implications.

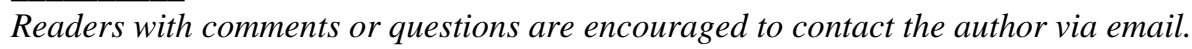




\section{Psychological Types}

This study is based upon psychological profiles that have been classified into two types: Type A (TA) and Type B (TB) (Friedman \& Rosenman, 1974). While many people exhibit traits of both, some people will tend to be dominant TA's or dominant TB's. When these individuals interact, friction resulting in lost productivity, wasted time, anger, or hostility towards each other is inevitable. Table 1 shows the characteristics of each type of behavior.

\begin{tabular}{|l|l|}
\hline \multicolumn{2}{|c|}{ Characteristics of Psychological Profiles } \\
\hline \multicolumn{1}{|c|}{ Type "A" } & \multicolumn{1}{c|}{ Type "B" } \\
\hline Aggressive & Calm \\
Overachievers & Patient with own efforts \\
Very productive & Patient with other person's efforts \\
Hostile when frustrated & Time constraints not important \\
Hard-driven & Less obsessed with achievement \\
Impatient & Easygoing \\
Competitive & Softspoken \\
Energetic & Tolerant towards slow pace \\
Sets high standards & Will not work hard without deadline \\
Role ambiguity & Very seldom stressed \\
Often stressful & Prefers work that is routine \\
Likes challenging work & Socially inclined \\
Less sociable & \\
\hline
\end{tabular}

\section{Objectives Of This Study}

The objectives of this study are twofold. First, is to determine the psychological profile of accounting professionals and accounting students in the Asian sector ${ }^{1}$. The second objective is to analyse the results of this study and compare to previous studies and extrapolate.

\section{Literature Review}

Initial research by Friedman \& Rosenman [1974] has shown that TA individuals are aggressive and struggle to achieve more in less time, and if necessary, against people or things. They also suggest that TA's are likely to be more productive than TB's who lack TA's obsession with achievement. TB's, on the other hand, are individuals who are more relaxed and patient and are more tolerant towards slowness. Additional research by Jamal [1985] further supports this.

Howard et al. [1977] examined the relationship of TA's to certain work patterns and job characteristics among a group of managers. In contrast to TB, TA's declined slightly with age. TA's and TB's differ significantly on two job factors: locked-in factor (inadequacy of education and training for the present and future job and the feeling that there is no alternative career path) and the contentment factor (competitiveness, supervisory responsibility, excessive workloads and conflicting demands). The TA's scored lower on both factors than TB's.

Besides the impact on work pattern, TA also affects performance through the moderation role of task variety. Lee et al. [1988] found that TA's outperform their TB counterparts on tasks high in variety because they set high performance goals, multitask, and have higher self-efficacy perceptions. Thus high-variety tasks should be given to TA's to motivate them.

\footnotetext{
${ }^{1}$ The sample was taken from accounting professionals and accounting students in Singapore. While it may be argued that this is from only one country in Asia, Singapore is a major business hub throughout Asia and cosmopolitan in nature thus very representative of the Asian sector.
} 
TA also can affect performance negatively. Burke and Dezca's [1982] study found significant relationships between TA and career outcome characteristics related to personal failure. TA managers were reported to be more insecure, less able to manage relationships well, less sociable, and were less satisfied with their career than TB's especially when only speed and impatience was considered.

Schaoubroeck and Williams [1993] provided insights to TA's performance in terms of judgement under uncertainty. TA's see the need to justify previous failure and to prove to themselves their level of competency after experiencing a failure. Persistency also contributed to escalating commitment.

Although employee involvement is important to many managers, Pace and Soujanen [1988] found that a TA manager behavior pattern may undermine employee involvement. Employees are constantly under pressure from disruptive and unsupportive managers who compete against time and other people and measure accomplishment in terms of quantity and speed.

Ivancevich and Matteson [1984] also considered work environment and found that TA's reported higher levels of stress in inflexible work environments. However, TB's experienced little distress in this setting.

Besides influencing individual performance, TB could also affect companies' performance. Hunt and Adams [1998] found that TB was significantly negatively related to companies' performance for those engaged in international business.

Concerning students, Waldron et al., [1980] discussed evidence that TA students achieve more academic honors and tend to earn higher grades. In addition, Siesser [1997] compared TA and TB types between and among business majors and art majors. The results showed that business majors have more TA tendencies within their personality than art majors do. TA's made up $93.9 \%$ of business majors while only $83.1 \%$ of art majors were TA's.

Where sex role orientation is concerned, DeGregorio and Carver [1980] found that the TA pattern agrees with a highly masculine sex role orientation while TB is associated with low masculinity, regardless of gender. The TB pattern was found to impede successful functioning among individuals who lack such a masculine orientation especially in areas of social interaction. Hence, these individuals face adjustment problems of high social anxiety, low social self-esteem, and depression. These problems were found to be more common among women.

Based on the above literature, it was expected that the results of this research would support the previous findings concerning TA and TB behavior. The methodology and results sections follow.

\section{Methodology}

Hypotheses

This study examines Asian accounting professionals and accounting majors in an effort to identify behavior patterns. Where job performance is concerned, Helmreich et al. [1980, 1988], Taylor et al. [1984] and Bluen et al. [1990] showed that performance (in quantitative and qualitative terms) is positively related to achievement striving and TB behavior while Lee et al. [1988] showed that Type A's perform better than Type B's in high variety tasks. Riordan \& Street [1999] further showed that Type A's contribute to rapid career development. Therefore, the following hypotheses are examined:

$\mathrm{Ha}_{1}: \quad$ A majority of accounting professionals exhibit TA behavior.

$\mathrm{Ha}_{2}$ : $\quad$ Rank is positively related to TA pattern.

$\mathrm{Ha}_{3}$ : Type A's hold higher rank than Type B's.

A previous study by Siesser [1997] showed that $93.9 \%$ of business majors are Type A's. Is this relatively the same among Asian accounting majors? As such, the following hypothesis is tested: 
$\mathrm{Ha}_{4}$ : A large majority of accounting majors are Type A's.

Waldron et al. [1980] and Spence et al. [1987, 1989] demonstrate that certain components of TA behavior are positively related to GPA. To test for this relationship, the following hypothesis is proposed:

Ha 5 : Type A's perform better academically than Type B's.

High masculine sex role orientation was found to be associated with TA pattern [DeGregorio \& Carver, 1980]. Therefore it is expected that more males will tend to exhibit TA behavior while more females will tend to exhibit TB behavior. This is tested in the following hypothesis:

$\mathrm{Ha}_{6}: \quad$ The majority of male accounting students will exhibit TA

behavior and the majority of females will exhibit TB behavior.

Sample

For the accounting professionals, two of the Big Five accounting firms agreed to participate in this study. Each of the two firms was given 30 questionnaires and 49 useable questionnaires were returned representing an $82 \%$ response rate. For the accounting students, data was collected from third-year students at a major university. Approximately 576 questionnaires were distributed and 300 questionnaires were deemed usable equating to a $52 \%$ response rate.

\section{Questionnaire}

Two versions of the questionnaire were used to collect the behavioral information needed for the survey. The first part captures demographic and performance information. The second part consists of 21 behavior profile assessment questions. Slight modification of the wording in the questionnaire was done to clarify terminology not familiar to the respondents. Scores for each individual were aggregated. A score less than or equal to 82 was considered a TB individual. An aggregated score between 83 and 86 inclusive indicated an individual who did not have dominant traits of TA nor TB. A score greater than or equal to 87 indicated an individual had TA characteristics.

\section{Statistical Test}

The hypotheses were examined using chi-square and one-way ANOVA statistics. In addition to these tests, correlation coefficients for the samples would be calculated to analyse the significance and the strength of the directional relationship respectively.

\section{Results and Analyses}

\section{Hypothesis 1}

The first hypothesis theorized that a large majority of accounting professionals would exhibit TA behavior. Table 2 shows the breakdown between the TA, TB and non-dominant behavior of the accounting professionals. As can be seen from the table, TB behavior was found to be the most common among the accounting professionals (43\%) while TA accounted for almost 39\%. Non-dominant behavior was found to exist among $18 \%$ of the responding accountants. It is possible that this may be due to TB's entering the profession and TA's being attracted to other professions. Due to the high cost of living in Singapore, many look towards high paying jobs to live a comfortable lifestyle. Therefore, TB's, even though they may not fit very well into the hurried nature of accounting and auditing work, enter the lucrative accounting profession. TA's, on the other hand, may be attracted to other more competitive, challenging, and high-variety jobs such as surgeons, lawyers, and entrepreneurs leaving many job opportunities available for TB individuals. 


\begin{tabular}{|c|c|}
\hline \multicolumn{2}{|c|}{$\begin{array}{c}\text { Table 2 } \\
\text { Behavior Distribution Among Accounting Professionals } \\
\mathbf{n = 4 9}\end{array}$} \\
\hline TA & $39 \%$ \\
\hline TB & $43 \%$ \\
\hline Non-dominant & $18 \%$ \\
\hline
\end{tabular}

\begin{tabular}{|c|c|c|c|}
\hline \multicolumn{4}{|c|}{ Table 3 } \\
Distribution of Behavior Pattern by Accounting Level \\
\hline Rank & TA & $\begin{array}{c}\text { Non- } \\
\text { dominant }\end{array}$ & TB \\
\hline $\begin{array}{c}\text { Audit Assistant } \\
(\mathrm{n}=15)\end{array}$ & $33 \%$ & $20 \%$ & $47 \%$ \\
\hline Senior (n=12) & $25 \%$ & $8 \%$ & $67 \%$ \\
\hline Supervisor (n=7) & $21 \%$ & $58 \%$ & $21 \%$ \\
\hline $\begin{array}{c}\text { Manager/Partner } \\
(\mathrm{n}=15)\end{array}$ & $33 \%$ & $47 \%$ & $20 \%$ \\
\hline
\end{tabular}

\begin{tabular}{|c|c|}
\hline \multicolumn{2}{|c|}{$\begin{array}{c}\text { Table 4 } \\
\text { Behavior Distribution Among Accounting Students } \\
\mathbf{n = 3 0 0}\end{array}$} \\
\hline TA & $25 \%$ \\
\hline TB & $55 \%$ \\
\hline Non-dominant & $20 \%$ \\
\hline
\end{tabular}

\section{Hypothesis 2 and 3}

Based on the evidence found in the Waldron et al. [1977] study that TA's achieve higher occupational status, this was tested. Surprisingly, there was no evidence found that any relationship exists between behavior and rank. In addition, as shown in Table 3, there appears to be no correlation indicating that TA behavior is found at the highest ranks and TB is nonexistent at the highest ranks. While it is evident from the sample that TB percentage as one moves up the ranks has decreased, it is very apparent that the nondominant trait also seems to be the dominant behavior style.

\section{Hypothesis 4}

This hypothesis tested whether a large majority of accounting majors are TA's based on the results of Siesser [1997] who found that the majority of business majors were TA's. The results of this study were quite the opposite. As can be shown in Table 4, the majority of students were found to be TB types (55\%). Since most of the respondents are Chinese, the Chinese culture may have played a role in determining the respondents' behavior patterns. Chinese society encourages values such as patience, humility, and self-control. Hence, Chinese culture may tend to favor TB behavior in individuals. Furthermore, the environment may also contribute to the result. As compared to the US society, the living pace in Singapore is not as fast. Thus, people here may lead a less hectic lifestyle and as such feel more relaxed and less aggressive.

\begin{tabular}{|c|c|c|c|c|}
\hline \multicolumn{5}{|c|}{$\begin{array}{c}\text { Table } 5 \\
\text { Distribution of Grades and Behavior Patterns }\end{array}$} \\
\hline $\begin{array}{l}\text { Behavior Pat- } \\
\text { tern }\end{array}$ & $\mathrm{A}$ & $\mathrm{B}$ & $\mathrm{C}$ & D or less \\
\hline TA $(n=54)$ & $26 \%$ & $40 \%$ & $34 \%$ & $0 \%$ \\
\hline $\mathrm{TB}(\mathrm{n}=124)$ & $1 \%$ & $52 \%$ & $41 \%$ & $6 \%$ \\
\hline $\begin{array}{l}\text { Non-dominant } \\
(\mathrm{n}=44)\end{array}$ & $4 \%$ & $63 \%$ & $31 \%$ & $2 \%$ \\
\hline
\end{tabular}

\begin{tabular}{|l|c|c|c|}
\hline \multicolumn{4}{|c|}{ Table 6 } \\
Distribution of Behavior Patterns and Gender \\
\hline & TA & TB & Non-dominant \\
\hline Males & $36 \%$ & $42 \%$ & $22 \%$ \\
\hline Females & $27 \%$ & $54 \%$ & $19 \%$ \\
\hline
\end{tabular}

\section{Hypothesis 5}

Previous research by Waldron et al. [1980] found that Type A's achieve higher grades. Based on this, similar results were expected in this study. Significant differences were found $(p=0.002)$ between the self-reported grades among the sample of students and their behavior pattern. Table 5 shows the distribution of the grades. While it is evident that TA's had more "A" grades, TB's also reported a very large percentage of "B" grades. From the grades reported, although differences exist, which behavior exhibits the better grades is still uncertain given that when combining $\mathrm{A}$ and $\mathrm{B}$ grades, TA's had $56 \%$ reporting those grades and TB's reported $53 \%$.

\section{Hypothesis 6}

The last hypothesis examined whether male students in general tended to exhibit TA behavior and females students exhibit TB behavior. This hypothesis was based on the results of DeGregorio and Carver's [1980] study. They found that higher masculine sex role orientation is associated with TA behavior no matter one's gender. Table 6 shows the distribution between male and female accounting students and their associated behavior. 
TB behavior is still the most common among both male and female accounting students in the sample of respondents. While it was theorized from past research that males should exhibit TA behavior more than females, this was true. However, among all males, the TB behavior was greater than the TA behavior that had been found in the DeGregorio and Carver study [1980]. As expected, more than half of the females exhibited the predicted (TB) behavior.

\section{Conclusions}

In this global village, CPA firms do not limit themselves to only one market or one country. They establish offices all around the world and employ local and foreign talent. Therefore, employees who come from different parts of the world with diverse personalities often have to work together. Due to these behavioral differences, conflicts could arise among accounting professionals. More importantly, undesirable behavioral characteristics that are incompatible with certain job designs may pose a threat to performance. Hence, an understanding of behavior types is important. As evidenced by the sample in this study, Asian accounting professionals and accounting students tend to display TB behavior while previous research has shown that TA behavior is dominant for the non-Asian professionals.

As examined in the research literature, TA behavior is generally related to high performance and rapid career advancement since TA's are often competitive and strive for achievement. They outperform TB's in high variety tasks. However, TA's can be easily irritated which can hurt their job performance and interaction with fellow workers. On the other hand, TB behavior is associated with better work quality. Compared to TA's, TB's are more relaxed, patient and have better social skills allowing them to interact with workers very easily.

What happens when a TA and a TB individual are part of an audit team or a consulting group? Problems will most likely occur but understanding the behavior patterns and the causes can be an initial step towards resolving these conflicts. The Asian market is becoming more interwoven with the world economy and Asian people will be working with their western business partners and clients on a more frequent basis. Future research should examine accounting majors from other educational institutions as well as other countries and accounting professionals from international CPA firms in order to understand the psychological profiles of current and future accounting professionals in an ever-shrinking world.

\section{References}

1. Bluen, SD, J Barling, and W Burns, "Predicting Sales Performance, Job Satisfaction, and Depression by Using the Achievement Striving and Impatient-Irritability Dimensions of Type A Behavior". Journal of Applied Psychology, (1990), 75 (2), pp. 212-16.

2. Burke, RJ and E Deszca, "Career Success and Personal Failure Experiences and Type A Behavior". Journal of Occupational Behavior, (1982), 3, pp. 161-170.

3. DeGregorio, E and CS Carver, " Type A Behavior Pattern, Sex Role Orientation, and Psychological Adjustment". Journal of Personality and Social Psychology, (1980), 39(2), pp. 286-293.

4. $\quad$ Friedman, M and RH Rosenman, "Type A and your Heart". New York: Knopf, (1974).

5. Helmreich, RL, JT Spence, WE Beane, GW Lucker, and KA Matthews, "Making It in Academic Psychology: Demographic and Personality Correlates of Attainment". Journal of Personality and Social Psychology, (1980), 39 (5), pp. 896-908.

6. Helmreich, R. L., JT Spence and RS Pred, "Making It Without Losing It: Type A, Achievement Motivation, and Scientific Attainment Revisited". Personality and Social Psychology Bulletin, (1988), 14, pp. 495504.

7. Howard, JH, DA Cunningham and PA Rechnitzer, "Work Patterns Associated with Type A Behavior: A Managerial Population". Human Relations, (1977), 30(9), pp. 825-836.

8. Hunt, RE and DC Adams, "Entrepreneurial Profiles and Company Performance: A Cross-cultural Comparison". International Journal of Commerce and Management, (1998), 8 (2), pp. 33-49.

9. Ivancevich, JM and MT Matteson, "A Type A-B Person-Work Environment Interaction Model for Examining Occupational Stress and Consequences". Human Relations, (1984), 37(7), pp. 491-514.

10. Jamal, M., "Type A and Job Performance: Some Suggestive Findings". Journal of Human Stress, (Summer 
1985), pp. 60-68.

11. Lee, C., PC Earley and LA Hanson, "Are Type As Better Performers?" Journal of Organizational Behavior, (1988), 9, pp. 263-269.

12. Pace, LA and WW Soujanen, "Addictive Type A Behavior Undermines Employee Involvement". Personnel Journal, (1988), 67 (6), pp. 36-42.

13. Riordan, DA and DL Street, "Type A Behavior in the Workplace - The Good, The Bad and The Angry, Where Do You Fit In?" Strategic Finance, (1999), pp. 28-32.

14. Schaubroeck, J. and S Williams, "Type A Behavior Pattern and Escalating Commitment". Journal of Applied Psychology, (1993), 78, pp. 862-867.

15. Siesser, SK, “Type A Behavior Among Business Majors in Comparison with Art Majors". Missouri Western State College, (1997).

16. Spence, J T, RL Helmreich and RS Pred, "Impatience versus Achievement Striving in the Type A Pattern: Differential Effects on Students' Health and Academic Achievement". Journal of Applied Psychology, (1987), 72 (4), pp. 522-528.

17. Spence, J T, RL Helmreich and RS Pred, "Achievement Striving, Scholastic Aptitude, and Academic Performance: A Follow-up to Impatience versus Achievement Striving in the Type A Pattern: Differential Effects on Students' Health and Academic Achievement". Journal of Applied Psychology, (1989), 74, pp. 176-178.

18. Taylor, MS, EA Locke and ME Gist, "Type A Behavior and Faculty Research Productivity: What Are the Mechanisms?" Organizational Behavior and Human Performance, (1984), 34, pp. 402-18.

19. Waldron, I., A Hickey, C McPherson, A Butensky, L Gruss, K Overall, A Schmader and D Wohimuth, "Type A behavior Pattern: Relationship to Variation in Blood Pressure, Parental Characteristics, and Academic and Social Activities of Students". Journal of Human Stress, (1980), March, pp. 16-27.

20. Waldron, I., S Zyanski, RB Shekelle, CD Jenkins and S Tannenbaum, "The Coronary-prone Behavior Pattern in Employed Men and Women". Journal of Human Stress, (1977), 3, pp. 2-18. 
Notes 